Running head: CAREER SUCCESS: CONSTRUCTING A MULTIDIMENSIONAL

Dries, N., Pepermans, R., Carlier, O. (2008). Career success: Constructing a multidimensional model. Journal of Vocational Behavior, 73 (2), 254-267. 


\title{
Career success: Constructing a multidimensional model
}

\begin{abstract}
A multidimensional model of career success was developed aiming to be more inclusive than existing models. In a first study, 22 managers were asked to tell the story of their careers. At the end of each interview, idiosyncratic career success "construct ladders" were constructed for each interviewee through an interactive process with the interviewer. The 42 superordinate career success operationalizations that came forward through this process were then used as input in a Q-sort study in which 30 subject matter experts (SMEXs) served as judges. Through multidimensional scaling (MDS), a model incorporating the different idiosyncratic meanings the interviewees attached to the career success construct was obtained. A two-dimensional configuration (affect - achievement vs. intra-personal - interpersonal) comprising 9 regions (performance, advancement, self-development, creativity, security, satisfaction, recognition, cooperation and contribution) was concluded upon as the optimal solution. Correspondences with earlier conceptual models of career success are spelled out.
\end{abstract}

Keywords

Career success; laddering interview method; Q-sort; multidimensional scaling 


\section{Career success: Constructing a multidimensional model}

\section{Introduction}

The "new" careers literature is grounded in the supposition of a substantial change affecting careers and the career success construct (Adamson, Doherty \& Viney, 1998; Dany, 2003; Sullivan, 1999). In particular, much has been written about the gradual displacement of the traditional, organization-based career and the old psychological contract with new types of career and the new, employability-orientated psychological contract (Argyris, 1960; Arthur, 1994; Briscoe, Hall \& DeMuth, 2006; Fugate, Kinicki \& Ashfort, 2004; Rousseau, 1995; Sullivan, 1999). Consequently, there has been a noticeable evolution in the way career and career success are defined. While Wilensky (1961) referred to career as a succession of related jobs, arranged in a hierarchy of prestige, through which persons move in an ordered (more-or-less predictable) sequence (p. 523), Super (1980) defined career as the combination and sequence of roles played by a person during the course of a lifetime (p. 282). Finally, Arthur, Hall and Lawrence (1989) defined career as the evolving sequence of a person's work experiences over time (p. 8), which is an established definition of career today (Arthur, Khapova \& Wilderom, 2005). This evolution from "jobs" to "experiences" was reflected in the post-modern turn in the social sciences during the late 1980s (Savickas, 1995), when attention increasingly shifted from the objective to the subjective world of work.

The objective face of career is mostly concerned with observable, measurable and verifiable attainments such as pay, promotion and occupational status, which have long been recognized as "the" hallmarks of career in many different societies (Nicholson, 2000). However, economic trends such as organizational delayering, downsizing and outsourcing have diminished the opportunity as well as the desire to have "traditional", upwardly mobile careers, and as such, the experience of objective career success (Evans, Gunz \& Jalland, 1997; Hall, 2002; Heslin, 2005; Reitman \& Schneer, 2003). Subjective career success, on the other 
hand, refers to career satisfaction about all aspects of career relevant to a specific individual (Greenhaus, Parasuraman \& Wormley, 1990). It is measured in terms of an individual's perceptions of his or her own success, based on perceptions of personal career accomplishments and future prospects (Aryee, Chay \& Tan, 1994; Judge, Cable, Boudreau \& Bretz, 1995; Melamed, 1996; Nabi, 1999). It is a combination of the internalized career success evaluations made by significant others and one's own evaluation of one's success, weighted against the careers of peers, and certain age-related or personal expectations about career (Betz \& Fitzgerald, 1987) and a sense of progress towards personally defined career goals (Hall, 1976; Wiese, Freund \& Baltes, 2002). Although the distinction between objective and subjective career success is generally underwritten by career scholars, Hall and Chandler (2005) stressed that careers are two-sided and that the literature should steer clear of "eitheror" discourse: “. . not that one vantage-point is more pertinent, but rather that the subjective career cannot be ignored - as it was in prior decades - particularly in today's career environment" (p. 156).

Rather than stating that the subjective career is "taking over" from the objective career, it would be more correct to assert that career scholars today are becoming increasingly aware of the fact that career success is as a social construction rather than an objective reality (Adamson et al., 1998; Chen, 1997; Collin \& Young, 1992; Mallon \& Cohen, 2000; Young, Valach \& Collin, 1996), a dynamic concept rather than a static truth (Savickas, 2005), evolving along with the historical and cultural contexts surrounding it (Stead, 2004; Young \& Collin, 2004). Older research departed too much from the assumption of career success as a variable that is perceived consensually by persons evaluating others' careers (Gattiker \& Larwood, 1986), as a result laying the foundation for the reification of career - the supposition that a career is a "real", material, demonstrable entity together with a fixation on 
terminology, which one considers as factual rather than as a complex and dynamic reality that can be interpreted in different ways (Evetts, 1992).

2. The construction of career success contextualized

The current study aims to dissect the meaning of the career success construct by applying the laddering interview technique as well as Q-sort methodology to generate a more inclusive model of what career success might mean to different people. Several recent publications have made apparent that career success can have a multitude of meanings, depending on the individual or subgroup constructing the meaning (Adamson et al., 1998; Collin \& Young, 1992).

First of all, the construction of meaning for career and career success is a historically and culturally specific process (Young \& Collin, 2004). Savickas (2000) described the "rise and fall" of career in North America by outlining the historical evolution from an agricultural to an industrial economy and finally, to the current-day knowledge economy, causing careers to be decreasingly regulated and linear (Arthur, 1994; Briscoe et al., 2006; Evetts, 1992; Fugate et al., 2004; Rousseau, 1995; Sullivan, 1999). With regard to culture, several authors have demonstrated that the career narratives of people from different countries vary. Dany (2003) described the European culture as bureaucratic, with servile obedience, risk aversion and strong commitment as key features. The US culture, on the other hand, is described as “contractual”; risk-taking and entrepreneurial, individualist attitudes are valued (Briscoe, Hall, Las Heras \& Unite, 2007). Other researchers compared prevalent career theories - that are mostly contextualized for White people in middle-class US environments (Blustein, 2001) - to career narratives studied in Austria (Chudzikowski, Demel \& Mayrhofer, 2007), China (Shen, Hall \& Fei, 2007), Costa Rica (Ogliastri, Caballero, Rodríguez \& Sabando, 2007), Japan (Taniguchi, 2007), Malaysia (Abdul-Ghani, Poon, Noordin, Briscoe \& Jones, 2007), 
Spain (Las Heras \& Zikic, 2007), and among Northern Plains American Indians (Juntunen et al., 2001).

Furthermore, sub-culture and socio-economic background can play an important role in the way people construct the meaning of career success (Stead, 2004). For instance, Sturges (1999) reported that interviewees who grew up in blue-collar environments indicated that their parents "did not have careers". Hennequin (2007) found, in line with Thomas (1989), that blue-collar workers create their own definition of career success, in which seniority, technical competence or the amount of danger experienced at work play a role.

Finally, and on a more individual level, developmental theories such as socialization and life-cycle processes may be relevant. Socialization processes are particularly relevant when it comes to the career success definitions of men versus those of women. For instance, certain cultures limit the desirability and possibility of women pursuing careers in "masculine" sectors by emphasizing their responsibility as "wife and mother" (Stead, 2004), while men are "breadwinners" or "providers" (Dyke \& Murphy, 2006; Parker \& Chusmir, 1992; Powell \& Mainiero, 1992; Russo, Kelly \& Deacon, 1991; Sturges, 1999). Moreover, several authors have found that the meaning attributed to career success can shift across generations (e.g. Dries, Pepermans \& De Kerpel, in press) as well as during one person's life cycle, depending on the career stage, the different life tasks and the development of the selfconcept (Lee et al., 2006; Poole, Langan-Fox \& Omodei, 1993).

\section{Recent studies on the meaning of career success}

There have been a few studies scrutinizing the actual topic of the career success construct and its dimensionality in itself (as opposed to its many research applications as a vaguely operationalized dependent variable). Based on an open-ended survey study, Gattiker and Larwood (1986) compiled a measure of career success consisting of five factors: job 
success, interpersonal success, financial success, hierarchical success and life success. Parker and Chusmir (1990), on the other hand, named their conception of the construct "life success", arguing that subjective career success tends to encompass factors from outside the career. They identified status/wealth, contribution to society, family relationships, personal fulfilment, professional fulfilment and security as relevant factors. Sturges (1999) and Nabi (2001) both reported finding two factors in their qualitative studies, i.e. external, or extrinsic, career success versus internal, or intrinsic, career success. Dyke and Murphy (2006) classified their findings on the meanings of career success under the four factors balance, relationships, recognition and material success; Lee et al. (2006) identified organization-based, personal and interlinked themes in interviewees' discourse about career success. Finally, Hennequin (2007) established three factors within the career success construct: material career success, psychological career success and social career success.

Much recent work refers to the urgent need for an adequate conceptualization of what career success means, both qualitatively and quantitatively (Poole et al., 1993; Heslin, 2005). According to Duxbury, Dyke and Lam (1999), as well as Heslin (2005), an expansion of the definition of career success is necessary, but more empirical work needs to be done to determine what such an expansion might entail. The current study answers calls for more studies that let people define career success in their own words and a more fine-grained analysis of different career success criteria (Heslin, 2005).

\section{Methods and results}

Two consecutive studies were conducted: the first study using the laddering interview technique to generate idiosyncratic meanings attributed to the career success construct; and the second study attempting to fit these meanings into an inclusive model of career success by using Q-sort methodology and multidimensional scaling (MDS). 


\subsection{Study 1: Laddering interview technique}

\subsubsection{Methods}

Measures and procedures. The laddering interview technique (e.g. Bourne \& Jenkins, 2005) was designed to access higher ("superordinate") levels of abstraction when interviewing people about the construct systems by which they organize their worlds. It has its roots in the repertory grid technique (Kelly, 1955). Study 1 started with interviewees being asked to tell the stories of their careers, choose their own themes and find coherence in their narratives. The reasons for starting off with career narratives were twofold: first, by letting the interviewees talk freely about their careers a certain "rapport" was created between researcher and interviewee that greatly facilitated the interactive laddering process in a later stage of the interview; second, allowing the interviewees to construct their career narratives at their own pace was necessary to be able to generate relevant constructs for the laddering exercise. The majority of interviewees began their career narratives by listing their jobs and employers from graduation to present; gradually they talked more about challenges and opportunities, turning points and decisions, and success and failure.

After completion of each narrative, which took about one hour on average, interviewee and researcher took a few minutes to recapitulate the main themes that arose from the career story. At this point, the interviewees were asked if they wanted to "do some ladders" - we used this phrasing as Bourne and Jenkins (2005) emphasized that an informal tone during the laddering interviews is beneficial to interviewees' openness to active participation. They were told that the goal of the exercise was to come to their own personal definition of career success. In a first step, each interviewee was asked to reflect again about the different meanings of career success that came forward in their personal and spontaneous account of their career. He or she was then asked to select the three most central constructs. 
Subsequently, these three constructs were the starting points of the laddering exercise for this interviewee, and were noted on three separate pages, at the bottom left. For each chosen career success construct, the question was asked "And what is the opposite of $[\ldots]$ ".? The answer was then recorded at the right side of the page and a double arrow was drawn between the two constructs to illustrate the dichotomy. Interviewees were then asked to choose which pole they preferred and why. The pole that was preferred got the title "preferred pole", the other "opposite pole". The "why" question was used to find the superordinate construct for the first concept on the preferred pole. The process continued in this manner, until no more superordinate constructs for a ladder could be found. This method was applied to all three career success ladders for each participant. Upon completion, the interviewees were asked to go over "their" ladders and to assess whether or not these actually conveyed their personal definition of career success. If, at the end of the exercise, an interviewee believed that his or her personal definition of career success was not adequately captured by his or her three ladders, one or more extra constructs from the career narrative were elaborated. For most interviewees, however, three constructs were sufficient.

Participants. Participation for the study was established within five Belgian organizations (from the banking, food, medical, metal and tobacco industry, respectively) located in the Dutch-speaking part of the country. Twenty-two managers participated in the laddering interview study; 17 were men (78\%) and 5 were women $(22 \%)$. The age of the participants ranged from 28 to 59; their average age was $40.05(s d=7.25)$.

\subsubsection{Results}

Sixty-nine career success ladders were constructed during the laddering interviews. In the content analyses process (conducted by each of the three authors to establish a certain degree of inter-rater reliability) no notable differences were found between contents of the ladders of men and women, nor between those of managers of different ages. 
Below, we have elaborated a ladder from one interviewee to demonstrate how we arrived at the superordinate career success constructs used throughout the follow-up study (see Figure 1). It illustrates how important it is to access superordinate meanings attributed to career success, as the interviewee started of with "learning", yet realized at the end of the exercise - to her own amazement - that what she really valued was "proving one's worth".

One of the themes that arose as central in the interviewee's views on career success was

"learning". The laddering interview proceeded as follows:

Interviewer (IR): As opposed to...?

Interviewee (IE): Not learning . . . or better yet, "routine". When you get stuck in your daily routine and never learn anything new ... I prefer "learning".

IR: And why do you prefer this pole over the other?

IE: I guess because I don't want to get stuck in that kind of routine . . . and by learning I can develop myself as a person . . . as opposed to stagnating in life, and in my career. The next level is immediately obvious to me! When I develop myself as a person, I feel like there is no stopping me, that I can keep going further. It makes me feel like I'm pushing back all boundaries.

IR: As opposed to what?

IE: I would say stagnation, but that was the previous level ... When someone is not crossing that boundary, they're just standing still.

IR: Which do you prefer and why?

IE: When you're standing still, you're just another face in the crowd . . This process is really confronting me with how much I value acknowledgement! I really don't want to be just a face in the crowd ... When I push back boundaries, that gets me acknowledgement. My boss and co-workers will then show me respect and show appreciation for what I do. The opposite is being a "grey mouse", when no one notices you or acknowledges what you do.

IR: And why is this so important to you? 
IE: Acknowledgement is very important to me because I am so competitive; I want to win the internal competition. My competitiveness really shows itself in many areas of my life. Don't challenge me to go for a run ... I hate losing!

IR: Why is that?

IE: You know, I guess maybe it has something to do with when I grew up . . . I was the youngest in my family and I had five older brothers! It wasn't easy for me to get noticed or heard. I taught myself to speak up against all those "tough" boys in my house. I learned how to make clear that I was a part of the family too! I always had this urge to prove my worth. I never want to be the smallest!

IR: So, "proving one's worth" versus "being the smallest"?

IE: Yes! Looking at the ladder, I'm kind of surprised. I started of with learning and ended up with proving one's worth! Not what I expected, but I guess it's accurate.

Although looking into the career success value systems of each of the 22 participants separately does provide interesting information for career scholars, it is not possible to report all of these findings here.

\subsection{Study 2: Q-sort technique and $M D S$}

\subsubsection{Methods}

Measures and procedures. The 69 career success ladders - in particular, the highest superordinate constructs of each preferred pole - that came forward in Study 1 were reassessed for use in Study 2, where they were used as input for expert analysis. The three authors served as independent assessors in the process of removing career success constructs that were identical to another construct, and thus redundant. Once inter-rater consensus was reached, 27 redundant constructs were removed. The remaining 42 career success constructs were used to prepare a Q-sort exercise (Parker, 2006). In compiling the Q-sort card deck, the three authors focused mainly on the highest superordinate career success constructs of the preferred poles. However, when the meaning of a construct was unclear in itself, or when an incorrect interpretation was possible, they made sure to label the corresponding Q-sort card 
so, that the meaning of the interviewee who generated the construct was adequately conveyed. Some examples are: "Being able to manage and shape one's own career; achieving everything single-handedly" and "Standing out; being the best at what one does". The full list of all 42 Q-sort cards originating from the laddering exercise in Study 1 can be consulted in the Appendix.

The 42 career success constructs were printed onto separate numbered cards and sent by post, along with an instructions letter, to a selected group of experts from the career counselling field. The experts were instructed to sort all cards into structured piles or " $\mathrm{Q}$ sorts". They were told to put two cards in the same pile if they were similar in meaning, and in a different pile if they were dissimilar (Parker, 2006). Furthermore, they were advised to only have piles of one card if they were absolutely certain they perceived it as dissimilar from all other cards. After sorting all 42 cards into piles, they were instructed to now see each pile as a category that required a label to capture the shared meaning of the constructs assigned to it. In order to ensure that the experts did not lose sight of the fact that the exercise revolved around the definition of career success, each card contained the phrasing "career success is..." in the top left corner. They were then asked to make up a document presenting their categorizations (labels and card numbers) and return it to the researchers.

Participants. Thirty subject matter experts (SMEXs) participated in the Q-sort study. We chose to work with career counselling experts in Study 2 as they possess much more knowledge of the way different people might look at the career success concept than does the general population, that might bias this type of exercise in using their personal preconceptions about success. To facilitate diverse perspectives half of the sample were students in their final Master year of Industrial and Organizational psychology at a large Belgian University (all students had received several courses on the topic of career counselling and the psychology of careers); the other half were Human Resources professionals specialized in career 
counselling. Nineteen of the SMEXs were women (63\%), eleven were men (37\%). The age of the students varied between 23 and $25(m=23.4 ; s d=0.74)$; the HR professionals were all between 25 and 50 years old $(m=37.07 ; s d=8.94)$.

Analysis. Statistical and interpretative analyses were performed on the career success categorizations that were obtained from the Q-sort study. The goal of these analyses was to determine the underlying structure of the 42 career success constructs in the form of an inclusive model. To achieve this, we investigated the appropriate graphical configuration of the career success constructs, and more specifically, the amount of underlying dimensions and clusters (i.e. "regions") in the data by applying multidimensional scaling (MDS). Multidimensional scaling is an exploratory technique that helps researchers determine the underlying structure in sets of data, and is considered particularly useful for the development of theory (Borg \& Groenen, 1997). As the aim of MDS is to represent perceived dissimilarities between constructs as metric distances in an $n$-dimensional space, the data from Study 2 needed to be transformed into a dissimilarity matrix first. For each pair of constructs, dissimilarities were calculated as the total number of experts that had not sorted them into the same category. It logically follows that values in the obtained dissimilarity matrix varied between 0 (i.e. all experts put constructs $x$ and $y$ together) and 30 (i.e. no expert put constructs $x$ and $y$ together). A classical ordinal MDS analysis was applied to the data matrix. The calculations were carried out using the ALSCAL algorithm of the SPSS program (SPSS 15.0). Subsequently, adequate labels were determined for the dimensions and regions through content analysis so as to add meaning to the model.

\subsubsection{Results}

Selection of the most appropriate MDS solution. In a first step, MDS solutions were computed for a one- to a five-dimensional model. To determine the appropriate number of dimensions for the career success model we first considered the observed stress values and $\mathrm{R}^{2}$ 
values for each number of dimensions, which were $.56(.31), .32(.57), .24(.69), .18(.77)$ and $.13(.83)$ respectively. We then plotted these stress values in a dimension $x$ stress graph to look for the "elbow". This method of determining optimal dimensionality is based on Cattell's scree test (see Derous, De Witte \& Stroobants, 2003). The resulting plot showed a slight elbow for the two-dimensional solution. However, some authors have stated that an elbow should seldom be accepted if stress values are higher than .10 (Kruskal \& Wish, 1978), which is definitely the case here. However, other authors have advised researchers using MDS not to consider Kruskal's rule-of-thumb alone in determining the appropriate number of dimensions for a model. First of all, simulation studies have demonstrated that stress values systematically increase when the number of constructs in the model increases (indicating that higher critical stress values would apply for a $42 \times 42$ matrix such as ours), and decrease when the number of dimensions increases (Spence \& Ogilvie, 1973; Wagenaar \& Padmos, 1971). Secondly, Borg and Groenen (1997) suggest that the "principle of simple structure" should be applied when selecting the appropriate dimensionality; the authors state that both over- and underestimation errors in proximities arise in MDS spaces of high dimensionality. Finally, a more substantive consideration is that of interpretability (Kruskal \& Wish, 1978). Based on all these concerns, a two-dimensional configuration was decided upon as the most appropriate solution.

Interpretation of the regions. A depiction of the two-dimensional spatial configuration of all 42 career success constructs is presented in Figure 3 (each construct is represented by a number; the associated labels can be consulted in the Appendix). To determine the number of regions in the model, a combination of methods was used.

Visual inspection of the two-dimensional configuration, along with additive tree modelling (T-Rex 4.0a1), resulted in four acceptable suggestions for delineation of the regions. In order to decide which of these four solutions was optimal, consistency-in-meaning 
(CIM) indices were calculated for all suggested regions. The CIM index was created by Derous et al. (2003) to provide some measure of the consistency in meaning of constructs that spatially belong to the same region. This is an important step in the analysis of a model, as MDS does not offer any information on the meaning of constructs, only on their proximity. Thus, the CIM index is a useful aid in deciding which constructs to group together into one region. According to Derous et al. (2003), "regions are interpreted consistently if all items belonging to that region (i.e. in the MDS solution) were sorted into piles which were labelled in a very similar way by experts" (p. 188). The CIM index is represented in the following equation: $\mathrm{CIM}=\left[1-\frac{(\delta L-1) i}{\left(N_{i} N_{\varepsilon}\right)-1}\right] \times 100$

CIM indices are calculated using three variables: $\delta L$, the number of labels with different meanings of all items graphically belonging to the same region $i$; $N_{i}$, the number of items belonging to the same region $i$; and $N_{\varepsilon}$, the maximum number of different labels that can be ascribed to the items of region $i$ - it follows logically that $N_{\varepsilon}$ is a constant value that equals the number of experts in the study $(N=30)$. In order to determine the $\delta L$ value for each region of each of the four solutions, content analysis was necessary. The three authors conducted this analysis separately: in a first step, we each made up a list of all category labels assigned by the SMEXs who completed the Q-sort exercise. We then grouped these labels together by meaning. Upon completion of this task, the three authors sat down together to reach inter-rater agreement on the number and content of different meanings that arose from the Q-sort exercise. We then made up a final list of meanings (17) and associated labels (173). In a next step we made a list, for each of the 42 career success constructs, of all category labels the constructs had been sorted under in Study 2. All of the above steps made it possible to "objectively" count the number of labels for each solution, so that CIM indices could be calculated (the CIM indices are reported in the Appendix). 
However, we included one additional step in our content analysis to determine which constructs to group together into regions. As is, the CIM index does not take into account the degree of consensus or dispersion between experts about the meaning of a construct. For instance, it is possible that constructs $x$ and $y$ have both been attributed 10 different meanings; however, it is well possible that $x$ was placed under a similar category by 21 SMEXs, and that the 9 other meanings attributed to $x$ were each only mentioned by 1 expert. For $y$ on the other hand, maybe each of the 10 meanings was agreed upon by 3 SMEXs. Intuitively, this would mean that there is more consensus on the meaning of $x$ than there is on the meaning of $y$, although this variable is not incorporated into the CIM index. In order to solve this issue, we mapped out each of the 42 career success constructs onto each of the 17 different meanings in a frequency matrix (the frequencies being the number of SMEXs that placed the construct under a category with a label falling under meanings 1-17).

Combining the results of all of the above analyses - visual inspection, additive tree modelling, and the two types of consistency-in-meaning evaluation - a final solution was decided upon by the authors, which is presented in Figure 3. Together with the information in the Appendix, Figure 3 presents the final solution consisting of nine regions: performance (1), advancement (2), self-development (3), creativity (4), security (5), satisfaction (6), recognition (7), cooperation (8) and contribution (9). The regions self-development, satisfaction and contribution were further divided into sub-regions based on the content analyses.

Insert Figure 2 about here

Interpretation of the dimensions. The first, horizontal, dimension is called affect versus achievement. Constructs at the affect end of this dimension belong to regions 5 (security), 6 (satisfaction), 7 (recognition), 8 (cooperation) and 9a (experienced contribution). The affect 
end of this dimension stands, more specifically, for feelings and perceptions people may have had throughout their careers that cause them to evaluate their career success as high or low. Constructs belonging to these regions are labelled "experiencing stability and job security" $\left(\mathrm{n}^{\circ} 28\right)$ and "believing to have achieved positive matters, in an ethical way" ( $\left.\mathrm{n}^{\circ} 27\right)$, among others. The other end of the dimension, achievement, refers to factual accomplishments characteristic of peoples' careers that cause them to evaluate their career success as high or low. Constructs at this end of the scale belong to regions 1 (performance), 2 (advancement), 3 (self-development), 4 (creativity) and 9b (factual contributions). Examples of construct labels are "getting promoted; climbing the ladder" $\left(\mathrm{n}^{\circ} 30\right)$ and "acquiring many experiences, inside one's job and out" (n²5).

The second, vertical, dimension is labelled intra-personal versus inter-personal. Constructs on the intra-personal side of the dimension belong to regions 3 (selfdevelopment), 4 (creativity), 5 (security) and 6 (satisfaction). The focus on this end of the dimension is on the career actor's "self", on aspects of his or her internal world that would cause him or her to evaluate career success as high or low. This is illustrated by the category labels belonging to these regions, e.g. "accomplishing one's own goals" $\left(\mathrm{n}^{\circ} 4\right)$ and "feeling healthy and happy, at home as well as at work" $\left(\mathrm{n}^{\circ} 9\right)$. Constructs on the inter-personal side of this dimension belonged to regions 1 (performance), 2 (advancement), 7 (recognition), 8 (cooperation) and 9 (contribution). Construct labels were "having a good understanding with one's employer - one that does not always require words" (n॰8) and "being an important link in the process that leads to organizational success" $\left(n^{\circ} 35\right)$, among others. Therefore, the interpersonal side of the dimension illustrates a focus on the relationships with the outside world career actors engage in - validations of their careers that take place outside their "self" that cause them to evaluate their own career success as high or low. 


\section{Discussion}

\subsection{Discussion of the proposed career success model}

The aim of the current paper was to generate a more inclusive model of career success. A model with four quadrants was decided upon as relevant for categorizing the different meanings attributed to the career success construct obtained from the two studies presented in this paper:

(I) inter-personal-achievement. Career success constructs belonging to this quadrant refer to factual accomplishments that characterize a career; the world external to the career actor's "self" acts as the source of validation. This quadrant contains three distinct "regions" of meaning: performance (i.e. success in terms of attaining verifiable results and meeting set goals); advancement (i.e. success in terms of progressing and growing, both in terms of level and experience); factual contribution (i.e. success in terms of contributing something tangible to the collective, for instance to an organization, as an individual);

(II) intra-personal-achievement. Career success constructs belonging to this quadrant refer to factual accomplishments that characterize a career; the career actor's "self" acts as the source of validation. This quadrant contains two distinct "regions" of meaning: self-development (i.e. success in terms of reaching one's full potential through selfmanagement of challenges and learning experiences); creativity (i.e. success in terms of creating something innovative and extraordinary);

(III) intra-personal - affect. Career success constructs belonging to this quadrant refer to feelings and perceptions that characterize a career; the career actor's "self" acts as the source of validation. This quadrant contains two distinct "regions" of meaning: security (i.e. success in terms of being able to meet one's financial and employment needs); satisfaction (i.e. success in terms of achieving personal satisfaction and happiness, both in the family and in the work domain); 
(IV) inter-personal - affect. Career success constructs belonging to this quadrant refer to feelings and perceptions that characterize a career; the world external to the career actor's "self" acts as the source of validation. This quadrant contains three distinct "regions" of meaning: recognition (i.e. success in terms of being adequately rewarded and appreciated for one's efforts and talents); cooperation (i.e. success in terms of working well together with peers, superiors, subordinates and clients); perceived contribution (i.e. success in terms of serving society through work, in an ethical way).

\subsection{Links with existing models of career success}

When putting our two-dimensional (affect - achievement vs. intra-personal - interpersonal) model of career success side by side with the models found in earlier studies (Dyke \& Murphy, 2006; Gattiker \& Larwood, 1986; Hennequin, 2007; Lee et al., 2006; Nabi, 2001; Parker \& Chusmir, 1991; Schein, 1978, 1990; Sturges, 1999), we see that the model proposed in this paper seems to be rather inclusive, in that it allows to fit all of the concepts of previous studies within its nine proposed "regions" (performance, advancement, self-development, creativity, security, satisfaction, recognition, cooperation and contribution). We established these correspondences with existing models of career success by carefully scrutinizing factors and items of the career success scales constructed by Gattiker and Larwood (1986), Schein (1978, 1990), Parker and Chusmir (1991) and Nabi (2001); in the case of Sturges (1999), Dyke and Murphy (2006), Lee et al. (2006) and Hennequin (2007) we dissected the qualitative data reported. Table 1 presents the hypothesized correspondences between the meanings attributed to career success in previous studies (wording is based on the original texts) and the model presented in this paper. 
When considering the distribution of the correspondences between the career success constructs of earlier studies and the model presented in this paper, we see that constructs fitting into our "satisfaction" region are by far most prevalent (24\% of the 114 constructs in Table 1 correspond to our conception of "satisfaction"); somewhat less prevalent were correspondences with the regions "contribution" (16\%), "recognition" $(15 \%)$ and "cooperation" (14\%); least prevalent were correspondences with "performance" $(10 \%)$, "advancement" (8\%) and "self-development" (4\%); the lowest correspondence was found with "creativity" $(3 \%)$. These numbers indicate that previous research into the meaning of the career success construct has focused mainly on the inter-personal - affect quadrant of career success, whereas the opposite quadrant, intra-personal achievement, has been stressed much less in the literature on career success - this quadrant, however, does link well to the literature on career self-management and protean careers (e.g. Hall, 2002).

Remarkably, the one career success construct that is most difficult to fit into our model of career success, is salary - one of the most frequently used measures in the literature (Heslin, 2005). Without further information on what is meant exactly "salary", it could be fitted into several different regions: in the sense of "receiving a fair salary" it would fit best within region 7, recognition; in the sense of "not having any financial burdens" it would be better fitted into region 5, security; and in the sense of "salary increases" we would fit it into region 2, advancement. In contrast, the current study attempted to use relatively unambiguous career success constructs, which was demonstrated by the high inter-rater agreement (i.e. between the three authors) reached at different points during the content analyses of the data and reflected in the high consistency-in-meaning (CIM) parameters (Derous et al., 2003) reported in the Appendix.

Another finding of interest is that our model of career success corresponds specifically well with the career anchors conceptualized by Schein $(1978,1990)$ : his technical/functional 
competence anchor corresponds quite well with our "performance" region; the security/stability anchor with "security"; the autonomy/independence anchor with the "selfdevelopment" sub-region "independence"; the entrepreneurial creativity anchor with "creativity"; and the service/dedication to a cause anchor with "contribution". This is an interesting finding, as career anchors literature has mostly been linked to career management, decision-making, and planning (King, 2004), but never explicitly to definitions of career success. It does seem that career anchors put a stronger emphasis on action, while career success refers to construct systems that help people organize their worlds; the emphasis on career identity is also less pronounced in definitions of career success, as people do not only use their career success construct systems to evaluate their own careers, but also those of others. Finally, career anchors are considered input variables of career, which precede action, whereas career success is generally conceptualized as a destination, a desired outcome of career (e.g. Hall, 1976). Nonetheless, the extensive and well-established literature on career anchors might provide useful input for answering the calls in the literature for an expansion of the definition of career success (Duxbury et al., 1999; Heslin, 2005).

\subsection{Limitations}

Although the proposed model of career success does appear to be more inclusive than previous models, it is certainly true that further external validation is necessary. By no means do we claim to have developed "the" model of career success. As with all single-standing studies, variables from the research context (i.e. culture, language, sample selection, researchers' preconceptions) have undoubtedly affected our model. The study was conducted in a homogeneous sample of Belgian managers, and should thus not be generalized to bluecollar workers or people from different cultural backgrounds without further validation. Also, variations in organizational settings and cultures, as well as industries, might affect career success conceptualizations of respondents. Furthermore, the majority of our sample were 
men, which may also have coloured the resulting findings. Also, the majority of our sample was in their thirties, which means that the distribution in terms of generations, and life and career stages was limited. In order to fully grasp the dynamics of career success definitions across and within life spans however, different types of designs (i.e. cross-sectional and/or longitudinal) would be needed. Finally, although applying the findings of Study 1 in a Q-sort follow-up study reduced the richness of information that was obtained from the laddering interviews, combining the constructionist approach with more positivist methods made it easier to come to a synopsis of its findings. Notwithstanding possible epistemological incongruities in combining these two paradigms, any qualitative study on the meaning of career success would at some point be subject to a loss of information richness, but by using expert analysis in the Q-sorts and, at a later point of analysis, multiple raters (i.e. the three authors) during the content analysis of the data, subjectivity of the data reduction was curtailed.

\subsection{Implications}

\subsubsection{Implications for research}

The most important research implication of a study looking into the meaning of the career success construct is how it should be measured consequently. The subjective career measures currently used in research (e.g. the career satisfaction scale by Greenhaus et al., 1990) have been criticized for their lack of broadness, as they do not encompass all possible dimensions people may use to define and evaluate career success (Arthur et al., 2005; Heslin, 2005).

However, even if it were possible to come to a list of "all possible" idiosyncratic criteria used by people to evaluate career success, transforming this knowledge into a workable measure of career success would still remain quite difficult. Further research is 
necessary to evaluate how new career measures can be developed that are both inclusive and workable. One suggestion is to work with weighted scales, in which all possible definitions of career success are incorporated, and respondents must indicate both the applicability of each item to their own career, as well as their perceived relevance in light of their personal definition of career success (Heslin, 2005). With such a design, both differences in career success (as measured by the weighted or unweighted applicability of the constructs to respondents' actual careers) and differences in career success definitions (as measured by the evaluated relevance of each construct) could be compared between groups (e.g. men versus women, white-collar versus blue-collar employees, older versus younger employees). However, in order to be truly inclusive, such a measure would have to contain the option of respondents adding more constructs to the scale while they are answering to it, should they feel that not all relevant constructs have been surveyed. It is clear that this would cause some methodological intricacies; nonetheless it would be interesting to test this type of designs in further research, and validate it alongside the other measures of career success in a variety of research samples. In any case, it is important that careers researchers reflect thoroughly about the implications different operationalizations of career success may have on subsequent research findings. It has been repeatedly demonstrated that different measures of career success (i.e. objective versus subjective measures, one-item measures versus multiple-item measures) yield different, sometimes opposing conclusions (Arthur et al., 2005; Boudreau et al., 2001; Hall \& Chandler, 2005; Judge et al., 1995; Nabi, 1999, 2001).

Another important topic concerns the dynamics of career success definitions: which contextual systems might influence the career success construct systems held by individuals? The generations literature argues that historical evolutions in society would cause intergenerational differences in conceptions of career and career success (Mirvis \& Hall, 1994; Dries et al., 2008). On the other hand, life-cycle processes influence career success construct 
systems within individuals as life priorities shift alongside their career stages (Lee et al., 2006; Poole, Langan-Fox \& Omodei, 1993). It is probable, for instance, that career actors entering parenthood will emphasize the "satisfaction" region more than young graduates, who might be more focused on "performance" (Lee et al., 2006). Finally, the "self-enforcing" nature of career must also be entered into the equation (Luhmann, 1995). Cognitive dissonance reduction processes most likely play a substantial role in individuals' constructions of career success (Dries et al., 2008; Sturges, 1999): to what extent do individuals seek out careers that fit their career preferences, or conversely, adapt their subjective definitions of what career success means to their own, objective career realities? Several past publications have tackled the interdependence between the subjective and the objective face of career (e.g. Hall \& Chandler, 2005). Furthermore, studies conducted in populations with careers that digress from the norm (e.g. blue-collar workers, part-time workers, people that have "derailed" or hit a glass ceiling) have been found to develop different definitions to better fit their own situations (Dany, 2003; Hennequin, 2007; Lee et al., 2006; Lucas \& Buzzanell, 2004; Nicholson \& de Waal-Andrews, 2005; Sturges, 1999; Thomas, 1989).

\subsubsection{Implications for practice}

Although studies on the meanings attributed to the career success construct may not be directly applicable to practice, they may help organizations design career systems, and individuals guide their own career self-management (Aryee et al., 1994). One of the most significant consequences of reification for both individuals and organizations is the assumption regarding what is the "normal" career and hence, what are "abnormal" career patterns (Evetts, 1992). One consequence of this is the devaluation and, as a result, inadequate rewarding of those in abnormal careers, e.g. experts in "lateral" career tracks or those who take a break from paid employment for personal reasons. It is important to acknowledge that 
organizations themselves contribute significantly to the continuation of the more traditional career concept. In their early careers, people's own personal definitions of career success are confronted with those of the organizations they work for, which often causes a re-definition of their own goals and roles (Duxbury et al., 1999). The reward policies of most organizations seem more accommodating for "masculine" goals; for example, parental leaves are often penalized through a subsequent stagnation in the career (Duxbury et al., 1999). However, at the same time it is a fact that job security, advancement opportunities and regular salary increases are no longer available to all employees (Rousseau, 1995). As a consequence, workforce segmentation - e.g. in the form of talent management programs (Dries \& Pepermans, in press) - together with a more diversified perception of what career success could mean to these different groups of employees and how their careers can be managed, becomes inevitable. An interesting implementation would be for organizations to establish frameworks of what they understand under "career success" utilizing the four quadrants of the model presented in the current paper. The adequate input for these frameworks could be drawn from HR strategy, and the organization's culture and values. Personnel evaluations could then incorporate these organizational career success frameworks, allowing for gap analysis and policy adaptations.

\section{References}

Abdul-Ghani, R., Poon, J.M.L., Noordin, F., Briscoe, J.P. \& Jones, E.A. (2007, August). Career success from a Malaysian perspective: Doing well by doing good. In J.P. Briscoe (Chair), Doing well by doing good across cultures? A global perspective on career success. Symposium conducted at the annual meeting of the Academy Of Management, Philadelphia, PA.

Adamson, S.J., Doherty, N. \& Viney, C. (1998). The meanings of career revisited: Implications for theory and practice. British Journal of Management, 9 (4), 251-259. 
Argyris, C. (1960). Understanding organizational behavior. Homewood, IL: Dorsey Press.

Arthur, M.B. (1994). The boundaryless career: A new perspective for organizational inquiry. Journal of Organizational Behavior, 15 (4), 295-306.

Arthur, M.B., Hall, D.T. \& Lawrence, B.S. (1989). Handbook of career theory. New York, NY: Cambridge University Press.

Arthur, M.B., Khapova, S.N. \& Wilderom, C.P.M. (2005). Career success in a boundaryless career world. Journal of Organizational Behavior, 26 (2), 177-202.

Aryee, S., Chay, Y.W. \& Tan, H.H. (1994). An examination of the antecedents of subjective career success among a managerial sample in Singapore. Human Relations, 47 (5), 487-510.

Baruch, Y. (2004). Transforming Careers: From Linear to Multidirectional Career Paths. Career Development International, 9 (1), 58-73.

Betz, N., \& Fitzgerald, L. (1987). The career psychology of women. Orlando, FL: Academic Press.

Blustein, D.L. (2001). Extending the reach of vocational psychology: Toward an inclusive and integrative psychology of working. Journal of Vocational Behavior, 59 (2), 171 182.

Briscoe, J.P., Hall, D.T., DeMuth, R.L.F. (2006). Protean and boundaryless career attitudes: An empirical exploration. Journal of Vocational Behavior, 69 (1), 30-47.

Briscoe, J.P., Hall, D.T., Las Heras, M. \& Unite, J.A. (2007, August). Doing well and doing good: Equations for career success in the United States. In J.P. Briscoe (Chair), Doing well by doing good across cultures? A global perspective on career success.

Symposium conducted at the annual meeting of the Academy Of Management, Philadelphia, PA. 
Borg, I., \& Groenen, P. (1997). Modern multidimensional scaling: Theory and applications. New York, NY: Springer.

Boudreau, J.W., Boswell, W.R., \& Judge, T.J. (2001). Effects of personality on executive career success in the U.S. and Europe. Journal of Vocational Behavior, 58 (1), 53-81.

Bourne, H. \& Jenkins, M. (2005). Eliciting managers' personal values: An adaptation of the laddering interview method. Organizational Research Methods, 8 (4), 410-428.

Chen, C. (1997). Career projection: Narrative in context. Journal of Vocational Education and Training, 49 (2), 311-326.

Chudzikowski, K., Demel, B. \& Mayrhofer, W. (2007, August). Do I look as if I care? Doing well in careers of three professional groups on Austria - A qualitative study. In J.P. Briscoe (Chair), Doing well by doing good across cultures? A global perspective on career success. Symposium conducted at the annual meeting of the Academy Of Management, Philadelphia, PA.

Collin, A. \& Young, R.A. (1992). Constructing career through narrative and context: An interpretative perspective. In R.A. Young \& A. Collin (Eds.). Interpreting career: Hermeneutical studies of lives in context (pp. 1-12). Westport, CT: Praeger.

Dany, F. (2003). 'Free actors' and organizations: Critical remarks about the new career literature, based on French insights. International Journal of Human Resource Management, 14 (5), 821-838.

Davidson, M.J. \& Cooper, C.L. (1992). Shattering the Glass Ceiling: The Woman Manager. London, UK: Paul Chapman Publishing.

Derous, E., De Witte, K. \& Stroobants, R. (2003). Testing the Social Process model on Selection through expert analysis. Journal of Occupational and Organizational Psychology, 76, 179-199. 
Duxbury, L., Dyke, L., \& Lam, N. (1999). Career development in the federal public service: Building a world-class workforce. Ottawa, Canada: Treasury Board of Canada Secretariat.

Dyke, L.S. \& Murphy, S.A. (2006). How we define success: A qualitative study of what matters most to women and men. Sex Roles - A Journal of Research, 55 (5), 357-372.

Dries, N. \& Pepermans, R. (2008). "Real" high-potential careers: An empirical study into the perspectives of organisations and high potentials. Personnel Review, 37 (1), 85-108.

Dries, N., Pepermans, R. \& De Kerpel, E. (in press). Exploring four generations' beliefs about career: Is "satisfied" the new "successful"? Journal of Managerial Psychology.

Evetts, J. (1992). Dimensions of Career: Avoiding Reification in the Analysis of Change. Sociology, $26(1), 1-21$.

Evans, M.G., Gunz, H.P. \& Jalland, R.M. (1997). Implications of organizational downsizing for managerial careers. Canadian Journal of Administrative Sciences, 14, 359-371.

Fugate, M., Kinicki, A.J. \& Ashfort, B.E. (2004). Employability: A psycho-social construct, its dimensions, and applications. Journal of Vocational Behavior, 65 (1), 14-38.

Gattiker, U. E., \& Larwood, L. (1986). Subjective career success: A study of managers and support personnel. Journal of Business and Psychology, 1, 78-94.

Gallos, J.V. (1989). Exploring women's development: implications for career theory, practice and research. In M.B. Arthur, D.T. Hall. \& B.S. Lawrence (Eds.), Handbook of Career Theory (pp. 110-132). Cambridge, UK: Cambridge University Press.

Gilligan, C. (1982). In a Different Voice: Psychological Theory and Women's Development. Cambridge, MA: Harvard University Press.

Greenhaus, J.H., Parasuraman, S. \& Wormley, W.M. (1990). Effects of race on organizational experiences, job performance evaluations, and career outcomes. Academy of Management Journal, 33 (1), 64-86. 
Hall, D. T. (1976), Careers in organisations. Glenview, IL: Scott, Foresman and Company.

Hall, D.T. (2002), Careers in and out of organizations. Thousand Oaks, CA: Sage Publications.

Hall, D.T. \& Chandler, D.E. (2005). Psychological success: When the career is a calling. Journal of Organizational Behavior, 26 (2), 155-176.

Hennequin, E. (2007). What 'career success' means to blue-collar workers. Career Development International, 12 (6), 565-581.

Heslin, P.A. (2005). Conceptualizing and evaluating career success. Journal of Organizational Behavior, 26 (2), 113-136.

Judge, T.A., Cable, D.M., Boudreau, J.W. \& Bretz, R.D. (1995). An empirical investigation of the predictors of executive career success. Personnel Psychology, 48 (3), 485-519.

Juntunen, C.L., Barraclough, D.J., Broneck, C.L., Seibel, G.A., Winrow, S.A., \& Morin, P.M. (2001). American Indian perspectives on the career journey. Journal of Counseling Psychology, 48(3), 274-285.

Kelly, G. A. (1955). The psychology of personal constructs. New York, NY: Norton.

King, Z. (2004). Career self-management: Its nature, causes and consequences. Journal of Vocational Behavior, 65, 112-133.

Kruskal, J.B. \& Wish, M. (1978). Multidimensional scaling. Beverly Hills, CA: Sage.

Las Heras, M. \& Zikic, J. (2007, August). To feel successful in one's career by doing good: Career success in Spain. In J.P. Briscoe (Chair), Doing well by doing good across cultures? A global perspective on career success. Symposium conducted at the annual meeting of the Academy Of Management, Philadelphia, PA.

Lee, M.D., Lirio, P., Karakas, F., MacDermid, S.M., Buck, M.L. \& Kossek, E.E. (2006). Exploring career and personal outcomes and the meaning of career success among 
part-time professionals in organizations. In R.J. Burke (Ed.), Research companion to work hours and work addiction (pp. 284-309). Cheltenham, UK: Edward Elgar.

Lucas, K., \& Buzzanell, P. M. (2004). Blue-collar work, career, and success: Occupational narratives of sisu. Journal of Applied Communication Research, 32, 273-292.

Lucas, K., Liu, M., \& Buzzanell, P. M. (2006). No limits careers: A critical examination of career discourse in the U.S. and China. In M. Orbe, B. J. Allen, \& L. A. Flores (Eds.), International and intercultural communication annual 28 (pp. 217-242). Thousand Oaks, CA: Sage.

Luhmann, N. (1995). Social systems. Stanford, CA: Stanford University Press.

Mallon, M. \& Cohen, L. (2000, July). My brilliant career? Using stories as a methodological tool in careers research. Paper presented at the annual International Conference on Organizational Discourse, London, UK.

Melamed, T. (1996). Career success: an assessment of a gender-specific model. Journal of Occupational and Organizational Psychology, 69 (3), 217-235.

Mirvis, P.H. \& Hall, D.T. (1994). Psychological success and the boundaryless career. Journal of Organizational Behavior, 15 (4), 365-380.

Nabi, G. (1999). An investigation into the differential profile of predictors of objective and subjective career success. Career Development International, 4 (4), 212-224.

Nabi, G.R. (2001). The relationship between HRM, social support, and subjective career success among men and women. International Journal of Manpower, 22 (5), 457-474.

Ng, T., Eby, L. T., Sorensen, K. \& Feldman, D. (2005). Predictors of objective and subjective career success: A meta-analysis. Personnel Psychology, 58 (2), 367-408.

Nicholson, N. (2000) Motivation-Selection-Connection: An Evolutionary Model of Career Development. In M. Peiperl, M. Arthur, R. Goffee, \& T. Morris (Eds.). Career 
Frontiers: New concepts of working life (pp. 54-75). Oxford, UK: Oxford University Press.

Nicholson, N. \& de Waal-Andrews, W. (2005). Playing to win: Biological imperatives, selfregulation, and trade-offs in the game of career success. Journal of Organizational Behavior, 26 (2), 137-154.

Ogliastri, E., Caballero, K. Rodríguez, C. \& Sabando, C. (2007, August). Doing well by doing good in personal careers: career success in Costa Rica. In J.P. Briscoe (Chair), Doing well by doing good across cultures? A global perspective on career success. Symposium conducted at the annual meeting of the Academy Of Management, Philadelphia, PA.

Parker P. (2006). Card sorts: A process of constructing personal narrative. In M. McMahon, \& W. Patton (Eds.). Career Counselling: Constructivist approaches (pp. 176-186). New York, NY: Routledge.

Parker B. \& Chusmir L.H. (1990). A generational and sex-based view of managerial work values. Psychological Reports, 66, 947-951.

Poole M.E., Langan-Fox J., \& Omodei M. (1993). Contrasting subjective and objective criteria as determinants of perceived career success. Journal of Occupational and Organizational Psychology. 66 (1), 39-54.

Powell, G.N. \& Mainiero, L.A. (1992). Cross-currents in the river of time: Conceptualizing the complexities of women's careers. Journal of Management, 18215-18237.

Reitman, F., Schneer, J.A. (2003). The promised path: a longitudinal study of managerial careers. Journal of Managerial Psychology, 18 (1), 60-75.

Rousseau, D.M. (1995), Psychological Contracts in Organizations: Understanding Written and Unwritten Agreements. Newbury Park, CA: Sage. 
Russo, N., Kelly, M. \& Deacon, M. (1991). Gender and sex related attribution: beyond individualistic conceptions of achievement. Sex Roles, 25 (5-6), 331-350.

Savickas, M. (1995). Current theoretical issues in vocational psychology: convergence, divergence, and schism. In W.B. Walsh \& S.H. Osipow (Eds.), Handbook of Vocational Psychology: theory, research and practice (2nd Edition, pp. 1-34), Mahwah, NJ : Lawrence Erlbaum Associates.

Savickas, M. L. (2000). Renovating the psychology of careers for the $21^{\text {st }}$ century. In A. Collin \& R. Young (Eds.), The future of career (pp. 53-68). Cambridge, UK: Cambridge University Press.

Savickas, M.L. (2005). The theory and practice of career construction. In S.S. Brown \& R.W. Lent (Eds.) Career Development and Counseling: Putting Theory And Research To Work (pp. 42-70). Hoboken, NJ: John Wiley \& Sons.

Shen, Y., Hall, D.T. \& Fei, Z. (2007, August). The evolution of career success: Doing well in China. In J.P. Briscoe (Chair), Doing well by doing good across cultures? A global perspective on career success. Symposium conducted at the annual meeting of the Academy Of Management, Philadelphia, PA.

Spence, I. \& Ogilvie, J.C. (1973). A table of expected stress values for random rankings in nonmetric multidimensional scaling. Multivariate Behavioral Research, 14, 355-365.

Stead, G.B. (2004). Culture and career psychology: A social constructionist perspective. Journal of Vocational Behavior, 64 (3), 389-406.

Sturges, J. (1999). What it means to succeed: Personal conceptions of career success held by male and female managers at different ages. British Journal of Management, 10 (3), 239-252.

Sullivan, S.E. (1999). The changing nature of careers: a review and research agenda. Journal of Management, 25 (3), 457-484. 
Super, D.E. (1980). A life span, life space approach to career development. Journal of Vocational Behavior, 13, 282-298.

Taniguchi, M. (2007, August). Change and continuity in career success in Japan. In J.P. Briscoe (Chair), Doing well by doing good across cultures? A global perspective on career success. Symposium conducted at the annual meeting of the Academy Of Management, Philadelphia, PA.

Thomas, R.J. (1989). Blue-collar careers: meaning and choice in a world of constraints. In M.B. Arthur, D.T. Hall \& B.S. Lawrence (Eds.). Handbook of Career Theory (pp. 354-379), Cambridge, UK: Cambridge University Press.

Verbruggen, M., Sels, L. \& Forrier, A. (2007). Unraveling the relationship between organizational career management and the need for external career counselling. Journal of Vocational Behavior, 71 (1), 69 - 83.

Wagenaar, W.A. \& Padmos, P. (1971). Quantitative interpretation of stress in Kruskal's multidimensional scaling technique. British Journal of Mathematical and Statistical Psychology, 24, 101-110.

Wiese, B. S., Freund, A. M., \& Baltes, P. B. (2002). Subjective career success and emotional well-being: Longitudinal predictive power of selection, optimization, and compensation. Journal of Vocational Behavior, 60, 321-335.

Wilensky, H.L. (1961). Careers, lifestyles, and social integration. International Social Science Journal, 12 (4), 553-558.

Young, R.A. \& Collin, A. (2004). Introduction: Constructivism and social constructionism in the career field. Journal of Vocational Behavior, 64 (3), 373-388.

Young R.A., Valach L., Collin A. (1996). A contextualist approach to career analysis and counselling. In D. Brown, L. Brooks (Eds.). Career Choice and Development (3rd edition, pp. 477-512). San Francisco, CA: Jossey-Bass. 
Career Success 34

Preferred pole

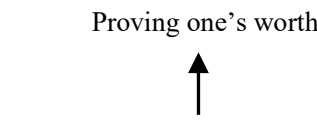

Winning the internal competition

$\uparrow$

Acknowledgement

$\uparrow$

Pushing back boundaries

$\uparrow$

Development

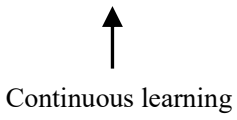

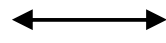
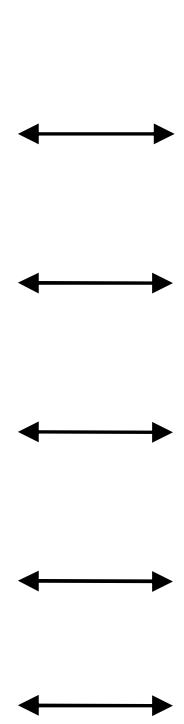

Opposite pole

Being the smallest

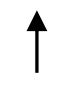

Losing

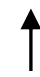

Being just another face in the crowd
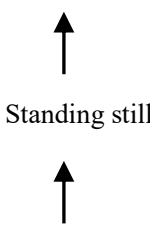

Stagnation

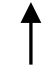

Routine

Figure 1. Example of a career success construct ladder obtained in Study 1. 
Inter-personal

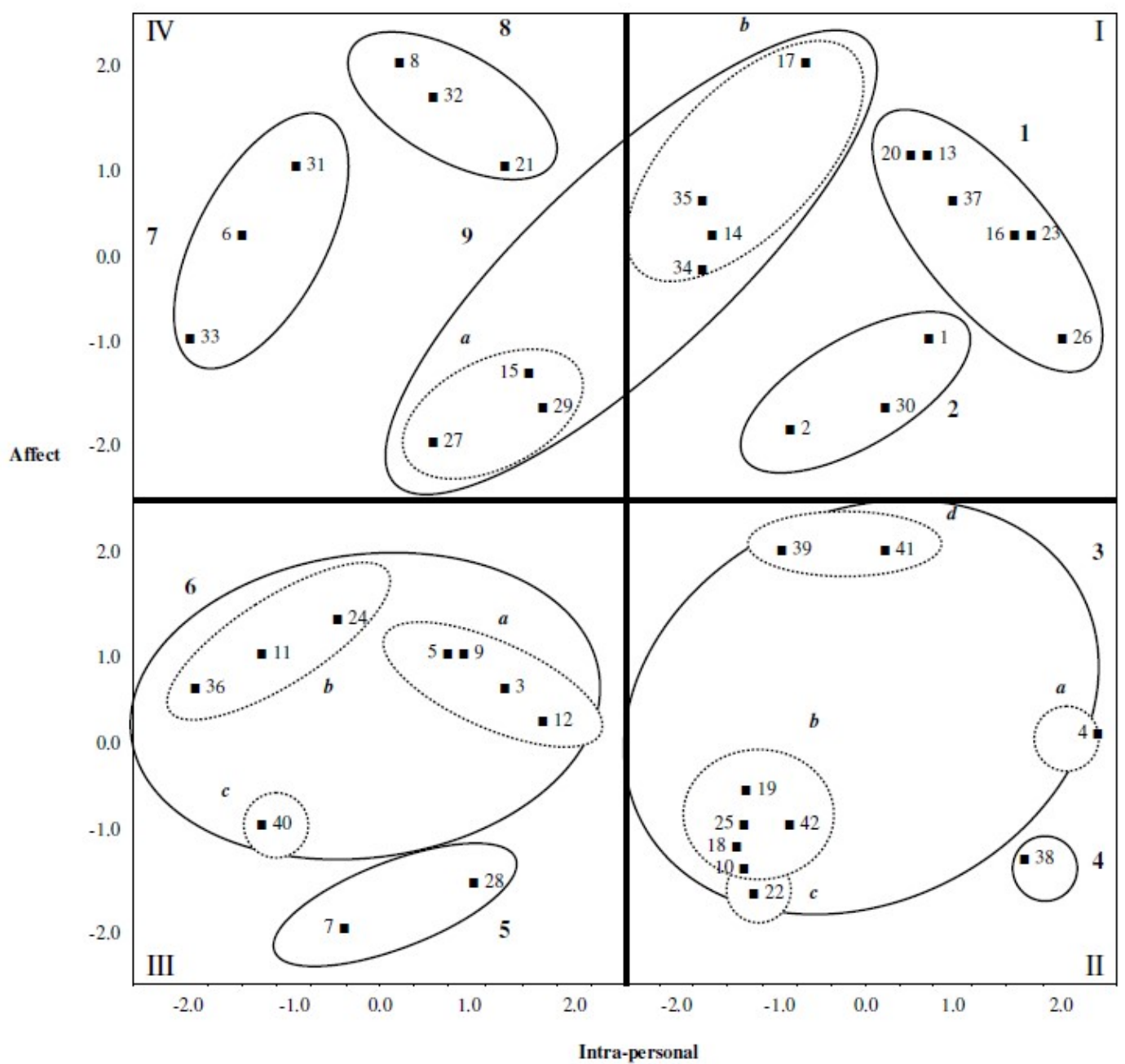

Achievement

Figure 2. Final MDS model of all 42 career success constructs mapped onto two dimensions and into 9 regions. 
Table 1

Hypothesized correspondences between existing models of career success and the model presented in the current study

Existing models of career success $\quad$ Correspondences with model of career success presented in the current study ${ }^{\mathrm{a}}$

Gattiker \& Larwood (1986)

1. Job success

2. Interpersonal success

3. Financial success

4. Hierarchical success

5. Life success

Schein $(1987,1990)^{\mathrm{b}}$

1. Technical/functional competence

2. General managerial competence

3. Security/stability

4. Autonomy/independence

5. Entrepreneurial creativity

6. Service/dedication to a cause

7. Pure challenge

8. Life style

Parker \& Chusmir (1991) ${ }^{\mathrm{b}}$

1. Status/wealth

2. Contribution to society

3. Family relationships

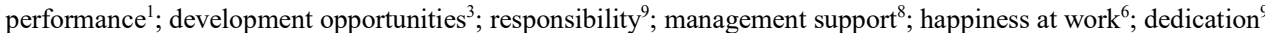

peer respect and acceptance ${ }^{8}$; good evaluations ${ }^{1}$; supervisor confidence ${ }^{8}$

fair compensation compared to peers ${ }^{7}$; high income compared to peers ${ }^{7}$

(opportunities for) promotion ${ }^{2}$; meeting career goals as planned ${ }^{3}$

happiness in private life ${ }^{6}$

being good at something ${ }^{1}$; achieve a high level of competence ${ }^{1}$; become an expert $^{1}$

being a general manager ${ }^{2}$; managing the efforts of others ${ }^{8}$; making decisions that affect people ${ }^{9}$

stability, continuity ${ }^{5}$; financial and employment security ${ }^{5}$; avoid risks ${ }^{5}$

freedom ${ }^{6}$; working without rules and constraints ${ }^{6}$

creativity ${ }^{4}$; building a business based on ideas ${ }^{4}$

helping other people ${ }^{9}$; contributing to society, making the world a better place ${ }^{9}$

seeking constant stimulation ${ }^{3}$; challenging problem-solving and competitive skills ${ }^{1}$

integrating work and personal life ${ }^{6}$

power, influence ${ }^{9}$; high income compared to peers ${ }^{7}$; good benefits ${ }^{7}$; recognition $^{7}$; salary increases ${ }^{2}$

helping others ${ }^{9}$; being useful ${ }^{9}$; making a difference ${ }^{9}$; improving well-being of the workforce ${ }^{9}$

happy and stable marriage ${ }^{6}$; being a good parent ${ }^{6}$; raising children successfully ${ }^{6}$ 
4. Personal fulfilment

5. Professional fulfilment

6. Security

Sturges (1999)

1. External career success

2. Internal career success

$\operatorname{Nabi}(2001)^{\mathrm{b}}$

1. Extrinsic job success

2. Intrinsic job success

Dyke \& Murphy $(2006)^{\mathrm{c}}$

1. Balance

2. Relationships

3. Recognition

4. Material success

Lee et al. $(2006)^{\mathrm{c}}$

1. Organization-based themes

2. Personal themes

3. Interlinked themes

Hennequin (2007) ${ }^{\mathrm{c}}$

1. Material career success

2. Psychological career success

3. Social career success inner peace, contentment, happiness ${ }^{6} ;$ personal worth $^{6}$, creativity $^{4}$; satisfaction, happiness ${ }^{6}$; self-respect ${ }^{6}$; enjoying non-work activities

competence, performance ${ }^{1}$; commitment $^{9}$; supervisor confidence ${ }^{8}$; acceptance by colleagues ${ }^{8}$; job satisfaction ${ }^{6}$

economic security ${ }^{5}$, job security ${ }^{5}$

financial rewards ${ }^{7}$; hierarchical level ${ }^{2}$; advancement ${ }^{2}$

influence $^{9} ;$ recognition $^{7} ;$ competence $^{1} ;$ personal achievement ${ }^{3} ;$ enjoyment $^{6} ;$ integrity $^{9} ;$ balance $^{6} ;$ receiving feedback $^{8} ;$ responsibility $^{9}$

equitable pay, fair income ${ }^{7}$; responsibility'; promotional opportunities

job happiness $s^{6} ;$ management support ${ }^{8}$; likable work ${ }^{6} ;$ likable colleagues $^{8}$; good performance evaluations ${ }^{1} ;$ supervisor confidence $^{8}$

happiness ${ }^{6}$; personal fulfilment ${ }^{6}$; content with life's direction ${ }^{6}$; freedom

stable relationship with partner and children $^{6}$, community $^{9} ;$ contribution $^{9} ;$ respect $^{8} ;$ support $^{8} ;$ team achievements ${ }^{8} ;$ recognition, status $^{7}$

being good at a challenging job ${ }^{1}$; being recognized as competent ${ }^{7}$; acceptance by clients ${ }^{8} ;$ recognition, acknowledgement

good salary'; being able to live good ${ }^{5}$; no financial burdens ${ }^{5}$

peer respect ${ }^{8}$; upward mobility ${ }^{2}$; appreciation/recognition ${ }^{7}$

having a life outside work ${ }^{6}$; learning, growing and being challenged ${ }^{3}$; fun and enjoyment/doing interesting work ${ }^{6}$

performing well ${ }^{1}$; having an impact/making a contribution

monetary rewards ${ }^{7}$; fringe benefits; hierarchical position ${ }^{2} ;$ number of promotions ${ }^{2}$

career satisfaction $^{6}$; job success ${ }^{1} ;$ interpersonal success ${ }^{8} ;$ life balance $^{6}$

social status ${ }^{7} ;$ recognition ${ }^{7} ;$ reputation 
${ }^{a}$ Note. The numbers next to each attributed meaning refer to supposed correspondences with the nine regions of the career success model presented in Figure 3 and in the Appendix.

${ }^{\mathrm{b}}$ Note. Survey study: the attributed meanings per factor were derived from the items in the career success scale presented in this paper (wording based on original text).

${ }^{\mathrm{c}}$ Note. Interview study: the attributed meanings per factor were derived from the career success constructs reported in the results section (wording based on original text). 


\section{Appendix}

Synopsis of the proposed career success model

\begin{tabular}{|c|c|c|c|c|c|c|c|c|c|}
\hline Quadrant $^{\mathrm{a}}$ & & Region & & & Q sorts & $\delta L$ & $N_{i}$ & $N_{\varepsilon}$ & $\mathrm{CIM}^{\mathrm{b}}$ \\
\hline \multirow[t]{9}{*}{ I } & 1 & Performance & & 13 & Successfully achieving envisioned goals & 13 & 6 & 30 & 94 \\
\hline & & & & 16 & Getting into a self-perpetuating cycle of motivation, action, results and growth & & & & \\
\hline & & & & 20 & Performing well, delivering efforts and getting results; demonstrating that one does a good job & & & & \\
\hline & & & & 23 & Going to great lengths to achieve good things & & & & \\
\hline & & & & 26 & Staying motivated and driven, continuously pursuing new goals & & & & \\
\hline & & & & 37 & Standing out; being the best at what one does & & & & \\
\hline & 2 & Advancement & & 1 & Being ambitious; wanting to progress, horizontally as well as vertically & 10 & 3 & 30 & 90 \\
\hline & & & & 2 & Experiencing plenty of opportunities to build a career, to grow within the organization & & & & \\
\hline & & & & 30 & Getting promoted; climbing the ladder & & & & \\
\hline \multirow[t]{10}{*}{ II } & 3 & Self-development & & & & 14 & 9 & 30 & 96 \\
\hline & & & $a$ & \multicolumn{2}{|c|}{ Goal attainment } & 8 & 1 & 30 & 76 \\
\hline & & & & 4 & Accomplishing one's own goals & & & & \\
\hline & & & $b$ & \multicolumn{2}{|c|}{ Continuous learning } & 10 & 5 & 30 & 94 \\
\hline & & & & 10 & Going through personal growth and development as a result of work experiences & & & & \\
\hline & & & & 18 & Achieving personal development by on-the-job learning and through various experiences & & & & \\
\hline & & & & 19 & Continuously learning in various ways so that one can continue to develop as a person and get ahead & & & & \\
\hline & & & & 25 & Acquiring many experiences, inside one's job and out & & & & \\
\hline & & & & 42 & Acquiring knowledge & & & & \\
\hline & & & $c$ & \multicolumn{2}{|c|}{ Self-expression } & 8 & 1 & 30 & 76 \\
\hline
\end{tabular}

22 Being able to express oneself through work and accomplishment 


\section{d Career self-management}

4 Creativity

5 Security

6 Satisfaction

38 Working creatively; accomplishing innovative, extraordinary ideas

28 Experiencing stability and (job) security

a Work-life balance

5 Being happy with all that one has and with all the possibilities present

9 Feeling healthy and happy, at home as well as at work

b Achievement satisfaction

\section{c Independence}

6 Being recognized for one's accomplishments; proving one's worth

8 Cooperation
39 Being able to manage and shape one's own career; achieving everything single-handedly

41 Creating opportunities in life

7 Having the freedom to buy what one desires; not experiencing financial restrictions

3 Being satisfied with one's work-life balance

12 Allowing one's family to play a significant role in life alongside one's career

11 Experiencing satisfaction and fulfillment brought about by one's own personal achievements

24 Feeling good; experiencing a warm and fuzzy feeling on the inside

36 Being proud of oneself and one's achievements

40 Pursuing independence as a major source of happiness

31 Being respected and appreciated by one's co-workers

33 Receiving a good, equitable compensation package; getting what one deserves, in line with one's performance

$12 \quad 2 \quad 30 \quad 82$

$\begin{array}{lll}10 & 1 & 30\end{array}$

$12 \quad 2 \quad 30$

82

$\begin{array}{llll}13 & 8 & 30 & \mathbf{9 5}\end{array}$

$\begin{array}{llll}9 & 4 & 30 & 94\end{array}$

21 Emphasizing people, as they make the difference in an organization 
32 Being amongst other people and cooperate with them

9 Contribution

\section{a Experienced contribution}

15 Personally contributing to the welfare of the organization - and as such, to that of society as a whole

27 Believing to have achieved positive matters, in an ethical way

29 Realizing that one person can make a world of difference in an organization

b Factual contribution

14 Demonstrating that one is a valuable asset to the organization

17 Steering a work team into a self-perpetuating cycle of motivation, action, results and growth

34 Being able to exert power or influence; making one's mark

35 Being an important link in the process that leads to organizational success 
${ }^{a}$ Note. I = inter-personal - achievement; II = intra-personal - achievement; III = intra-personal - affect; IV = inter-personal - affect.

${ }^{\mathrm{b}}$ Note. $\mathrm{CIM}=$ consistency-in-meaning index (Derous et al., 2003). 